\title{
Configurações
}

Revista Ciências Sociais

\section{Trabalhos de grupo no ensino da Sociologia: práticas, discursos e tensões}

Teamwork in teaching Sociology: practices, discourses and tensions

Travaux en groupe dans l'enseignement de la Sociologie : pratiques, discours et tensions

SOFIA BENTO, ROSALINA COSTA e EMÍLIA ARAÚJO

\section{(2) OpenEdition}

Journals

\section{Edição electrónica}

URL: https://journals.openedition.org/configuracoes/14535

DOI: 10.4000/configuracoes. 14535

ISSN: 2182-7419

\section{Editora}

Centro de Investigação em Ciências Sociais

Edição impressa

Paginação: 139-158

ISSN: 1646-5075

Refêrencia eletrónica

SOFIA BENTO, ROSALINA COSTA e EMÍLIA ARAÚJO, «Trabalhos de grupo no ensino da Sociologia: práticas, discursos e tensões», Configurações [Online], 28 | 2021, posto online no dia 28 dezembro 2021, consultado o 30 dezembro 2021. URL: http://journals.openedition.org/configuracoes/14535 ; DOI: https://doi.org/10.4000/configuracoes.14535 
BENTO, Sofia; COSTA, Rosalina; ARAÚJO, Emília - Trabalhos de grupo no ensino da Sociologia: práticas, discursos e tensões. Configurações [em linha]. 28 (2021) p. 139-158.

\title{
Trabalhos de grupo no ensino da Sociologia: práticas, discursos e tensões
}

\author{
SOFIA BENTO* \\ Universidade de Lisboa e SOCIUS/CSG \\ ROSALINA COSTA** \\ Universidade de Évora e Centro Interdisciplinar de Ciências Sociais - CICS.NOVA \\ EMÍLIA ARAÚJ0*** \\ Universidade do Minho
}

\begin{abstract}
Resumo
Neste texto, as autoras analisam a relevância dos trabalhos de grupo para o ensino da Sociologia, identificando alguns dos desafios que esta metodologia de ensino e aprendizagem impõem. O texto apoia-se na revisão da literatura, pesquisa documental e análise de resultados de um questionário respondido por estudantes que frequentam unidades curriculares de Sociologia. Os resultados indicam que os trabalhos de grupo são perspetivados pelos e pelas estudantes como uma metodologia relevante, com elevado potencial para a aquisição e o treino de competências. Todavia, indicam também, a necessidade de serem profundamente repensados no contexto dos objetivos de cada unidade curricular e plano de estudos.
\end{abstract}

Palavras-chave: trabalho de grupo, ensino, Sociologia, método, resultado.

\section{Abstract \\ Teamwork in teaching Sociology: practices, discourses and tensions}

In this text, the authors analyse the relevance of team-based work in teaching and learning Sociology, identifying some of the challenges brought about by this methodology. The text is based on a literature review, documentary research and analysis of the results of a survey with Sociology students. The results indicate that team-based work is considered a relevant methodology, with a high potential for obtaining and training skills in Sociology. /In addition, they also indicate the need to be deeply rethought

***E-mail: era@ics.uminho.pt | ORCID ID: https://orcid.org/0000-0003-3600-3310 
considering the objectives of each curricular unit, as well as the objectives of the study plan.

Keywords: teamwork, teaching, Sociology, method, result.

\section{Resumé}

Travaux en groupe dans l'enseignement de la Sociologie : pratiques, discours et tensions

Les auteurs de ce tex te analysent la pertinence des travaux en groupe dans l'enseignement et l'apprentissage en Sociologie, en identifiant certains des défis posés par cette méthodologie. Le texte repose sur un examen de la littérature, une recherche documentaire et l'analyse d'une enquête menée auprès d'étudiants en Sociologie. Les résultats indiquent que les travaux en groupe sont considérés par les étudiants comme une méthodologie pertinente, ayant un fort potentiel pour l'acquisition et la formation de compétences. Néanmoins, les étudiants indiquent également la nécessité que les travaux en groupe soient repensés en profondeur en tenant compte des objectifs de chaque unité d'enseignement et du plan d'études.

Mots-clés: travaux en groupe, enseignement, sociologie, méthode, résultat.

\section{Introdução}

Renata S. Schevisbiski (2008, p. 7) afirma que "A Sociologia precisa encarar o desafio de tornar-se uma educação viva frente ao predomínio de um ensino enciclopédico." Ainda segundo a autora, tal não significa transformar o ensino numa encenação utilitarista orientada para a ação, tão pouco descomprometer a docência da atividade de acompanhamento e avaliação. Trata-se, principalmente, de interligar os conteúdos programáticos e resultados de aprendizagem da Sociologia com os desafios da sociedade, favorecendo o desenvolvimento de competências de identificação e resolução de problemas e que contam com a consolidação de saberes teóricos.

As metodologias de ensino-aprendizagem baseadas em trabalho de grupo são teoricamente entendidas como metodologias que favorecem a exposição de estudantes a ambientes criativos, desafiantes e com alto potencial de simularem os contextos reais de trabalho que irão enfrentar, assim como a contextos de debate, crítica e reflexão teóricas. Alinhado com estes pressupostos, nos últimos anos têm surgido Unidades Curriculares (UC) designadas de Laboratórios, Oficinas ou Ateliês, cuja orientação é promover espaços de discussão, debate e treino de competências que estão para além da aquisição estrita de saberes teóricos e metodológicos e que configuram os resultados de aprendizagem no Ensino Superior (Dias e Soares, 2017; Dias, 2019; Dias, s.d.). 
Entre outras, estas metodologias oferecem duas contribuições principais: i) a articulação entre teoria e prática e ii) a melhoria do saber-estar dos licenciados nos mais diversos contextos de trabalho. Nos últimos anos, tem havido inúmeras recomendações no sentido da adoção de abordagens ativas baseadas em a) tutorias a grupos de trabalho, b) atividades de projeto desenvolvidas ao longo do semestre, c) uso de competências várias, tais como a colaboração na pesquisa, o acesso ao campo e argumentação face aos interlocutores e d) estágios. A pandemia gerada pelo SARS-CoV-2 mostrou, ainda, que o trabalho em grupo pode assumir formas diversas em ambientes digitais, de modo transversal nas mais diversas áreas do saber (QS, 2021). Acrescente-se que vários dos relatórios de avaliação de cursos de licenciatura em Sociologia elaborados pelas respetivas CAE (comissões de avaliação externa) disponibilizados no website da A3ES (2021)1, relativos a 2015, dão conta do interesse no investimento em metodologias que envolvam os estudantes na aprendizagem, através da sua inserção em projetos, estágios e trabalhos de grupo orientados para a resolução de problemas.

Tal como notado por sociólogos e sociólogas com responsabilidades na construção do campo da Sociologia em Portugal (Costa, 2018; Machado, 2020), o ensino nesta área confronta-se constantemente com a tensão entre o desenvolvimento de saberes e competências teóricas e as aprendizagens de tipo mais "prático." Por isso, os debates acerca das funções da Sociologia e a sua profissionalização, assim como a discussão em torno do papel do ensino de tipo individualizado versus coletivo, importam para a análise do modo como o trabalho de grupo pode ser perspetivado na Sociologia (Caria et al., 2012). Entre outras, esta metodologia é também estimulada enquanto meio de intensificar a profissionalização, dotando o diplomado em Sociologia de saberes que são valorizados no mercado de trabalho (Ramos et al., 2018).

Neste contexto, parecem-nos, por isso, relevantes as análises mais aprofundadas sobre as representações e os usos do trabalho de grupo no ensino da Sociologia, particularmente a nível da licenciatura. Este tex to surge nesse ensejo, enfatizando sobretudo as experiências e a visão dos e das estudantes. De modo transversal e complementar, procura-se também identificar e descrever o conjunto de variáveis que podem tanto robustecer como enfraquecer o desígnio do trabalho de grupo, favorecendo ou inibindo aprendizagens intrinsecamente relacionadas com as expectativas e os modos de implementação desta metodologia. Para o efeito, procuraremos reunir e contrastar informação proveniente de duas fontes: i) revisão de literatura sobre o uso de trabalhos de grupo no Ensino Superior); e ii) resultados de um questionário aplicado a estudantes de

1 A Agência Nacional de Avaliação e Acreditação de Cursos do Ensino Superior disponibiliza estes relatórios no seu website. De modo a não marcar nenhum curso em especial, optamos por referenciar todos. 
três Instituições de Ensino Superior (IES) portuguesas atualmente a frequentar e/ou que tenham concluído UC da área disciplinar da Sociologia.

\section{Fundamentação teórica}

Podemos encontrar as raízes da aprendizagem focada no aluno nas abordagens de pensadores como Dewey (1938), Lewin (1951), Freire (1970). Freire (1970) afirmou que os projetos educativos são projetos de mudança e de emancipação. Defendeu também que a forma como se ensina e se aprende está intrinsecamente condicionada pelo contexto social. Por isso, insurgia-se perante a transmissão de saberes baseada na distribuição de papéis hierárquicos, entre docentes e discentes, que se traduzia numa educação "bancária", em contraponto à possibilidade de uma educação problematizadora. $\mathrm{Na}$ sua apologia do ensino pelo diálogo, Freire (1970) declara a importância do mundo do aluno, dos seus conhecimentos e expectativas.

Quanto à Sociologia, esta insiste na necessidade de aproximar o ensino dos públicos estudantis, favorecendo a mobilidade social. Apesar dos desencontros teóricos no que respeita à definição das competências a integrar no ensino da sociologia (Machado, 2020), podemos afirmar que esta se constitui como corpus de conhecimento, e práticas, crítico dos sistemas e dos modelos educativos (Berger, 1986; Lahire, 2014). A Sociologia afirma-se também como território privilegiado para a abertura das práticas pedagógicas a métodos de ensino pró-ativo. Com efeito, a Sociologia é uma ciência da problematização, da desconstrução do mundo, que o interroga persistentemente (Mills, 1982; Silva, 2017) e tem no exercício contínuo da reflexividade um dos eixos propulsores fundamentais da aprendizagem, porquanto transformativo e favorecido pela "agência" do sujeito. Como afirma Sue Clegg (2005, p. 149), teorizando acerca do ensino-aprendizagem e mudança no ensino superior, "precisamos de ter um foco claro sobre a agência dado que só impactos de mudanças macroestruturais são medidos através da compreensão de atores específicos e da sua criatividade e resistência”.

Concomitantemente, e ainda que não se trate de um processo uniforme, o ensino baseado em trabalho de grupo tem sido cada vez mais adotado no ensino superior nas variadíssimas áreas científicas e usado como justificativa para o reforço dos resultados de aprendizagem (Dias, s.d.). O trabalho de grupo é, deste modo, apresentado como forma de os estudantes mobilizarem diversos conhecimentos e competências, preenchendo os tempos de aula com a aplicação concreta de conhecimentos e em regime de relativa autonomia. Nos estudos em inovação pedagógica, sublinham-se os benefícios do trabalho em grupo, nomeadamente o nível mais elevado de empenho dos e das estudantes, o desenvolvimento da capacidade crítica e os resultados positivos em termos de retenção de estudantes (Michaelsen e Sweet, 2011). Na conceção 
preconizada por estes autores, os elementos do grupo realizam, previamente, leituras e estudo individual, sendo que as sessões em aula começam com uma aferição à compreensão dos materiais lidos. O balanço é discutido no grupo de trabalho, que assim negoceia o entendimento dos elementos propostos para responder a velhas e novas questões. Da parte do docente, a aula centra-se no esclarecimento de dúvidas levantadas em sala e em termos de avaliação é aplicado um questionário medindo o contributo de cada um dos elementos para assim distinguir a participação dos vários estudantes.

O trabalho de grupo faz parte de um conjunto de metodologias reconhecidas por conduzirem os estudantes, em várias fases de aprendizagem, a melhorias que coincidem com a diversidade de desafios que exigem tanto conhecimentos e treinos de técnica, como de saber estar (Smith et al. 2007, p. 131). No final dos anos 60 do século XX, relatando a avaliação numa UC da Sociologia na Universidade do Illinois, Pape e Miller (1967) enfatizavam as vantagens do trabalho colaborativo em Sociologia. O trabalho em grupo despertou igualmente outras abordagens ativas como a aprendizagem colaborativa ou a aprendizagem baseada em problemas (PBL, problem based learning). Neste modelo pedagógico, convidam-se os estudantes e as estudantes a aprender através do seu envolvimento ativo em torno de problemas reais (Dochy et al., 2003). A partir dos anos 1970, a Universidade de Maastricht aplicou o conceito em todos os cursos e faculdades e, mais tarde, estendeu-o, também, à investigação. A metodologia do trabalho de grupo surge, então, como uma resposta ajustada ao ensino das aptidões de investigação de forma interativa, mais especificamente focado no pensamento crítico, na criação e na execução de um projeto de investigação, na redução da literacia de informação, na recolha de dados/ fonte, na seleção, na análise qualitativa e/ou quantitativa, na interpretação, na redação e na argumentação (Edlab, 2017). Outra das vantagens frequentemente apontada tem sido o nível de conhecimento que proporciona, nomeadamente a diferença entre aprendizagem "profunda" e aprendizagem "superficial" (Atherton, 2009; Bailey, 2011; Millis, 2014).

$\mathrm{Na}$ sociologia da ciência, a abordagem das controvérsias, aplicada no fim dos anos 1970 por Michel Callon e retomada nos anos 80 do século passado por Bruno Latour, constitui uma experiência reconhecida neste domínio, institucionalizada na École Nationale Supérieure des Mines de Paris, onde se apostou no trabalho em grupo para explorar a produção do conhecimento e da ciência. O método consiste em solicitar aos estudantes, através de metodologias de recolha documental e de terreno, o estudo de uma controvérsia, pressupondo que tal implica a mobilização de conhecimento científico não estabilizado, caracterizado por níveis elevados de incerteza para os atores envolvidos (Venturini, 2010; Callon, 1981). Noutra área de ensino-aprendizagem em sociologia, Bulanda e Frye (2020, p. 272) analisam o uso da metodologia de grupos de trabalho, dando conta das múltiplas vantagens e desafios 
que implica e concluindo que se trata de "uma estratégia de ensino altamente estruturada e imersiva que enfatiza a aprendizagem ativa por meio de equipes de pares." Monson (2017) declara que projetos de pesquisa em grupo são uma pedagogia eficaz para cursos de métodos de pesquisa em sociologia, e aponta algumas diretrizes para a composição de grupos de professores orientados para desenvolver projetos de pesquisa. Outros autores (Stein et al 2015; Morris et al, 2020) enfatizam a relevância do trabalho de grupo na promoção da integração de pessoas de etnia/raça distintas, e do desempenho individual, no geral (Monson, 2017). A metodologia de grupo de trabalho (GT) pode ser combinada com a resolução de problemas e análise de casos (Eglitis et al., 2016). Yavuz (2020) documenta o processo de colocar os alunos a editar uma obra. Outros estudos falam da mentoria, e do interesse em integrar estudantes a orientar e a participar nos trabalhos em anos mais iniciais (Monson, 2017). Todavia, também são apontadas diversas dificuldades. Segundo Caulfield e Hodges (2006), há estudantes que resistem aos trabalhos de grupo, muito embora reconheçam a sua importância. Huggins e Stamatel (2015) concluem que os resultados de aprendizagem podem ser obtidos da mesma forma, utilizando ou não metodologia de grupo de trabalho. Todavia, afirmam que os grupos de trabalho parecem favorecer o interconhecimento com o professor e entre alunos, de forma mais estreita.

No caso particular da Sociologia, as metodologias de ensino foram ganhando formas diferentes, quer nas diversas universidades, quer também internamente, em cada universidade. Em contexto português, por circunstâncias várias, incluindo, por um lado, a crescente subespecialização de áreas e, por outro, a dificuldade de diálogo interno sobre práticas e métodos de ensino, a Sociologia permaneceu ao longo dos anos entendida como uma disciplina de papel e lápis. As alterações introduzidas nos curricula com a reforma de Bolonha não parecem ter sido suficientes para superar esta reputação errónea. Na prática, observa-se que no seio da universidade "massificada" faltam instrumentos que garantam a disponibilidade de meios adequados a práticas de ensino participativas e experimentadoras, desde o tamanho das turmas, à organização e avaliação do trabalho docente. Todavia, como se disse acima, os grupos de trabalho continuam a estar altamente presentes e a constituir um dos alicerces fundamentais das metodologias de ensino e de aprendizagem. De modo a produzir alguma reflexividade a propósito de um método que é relativamente comum no ensino da Sociologia, procuramos neste tex to entender um pouco mais como os estudantes em Sociologia experienciam e avaliam a metodologia do trabalho de grupo. Em última instância, almeja-se contribuir para um debate que deve implicar posteriormente tanto docentes, como estudantes e, necessariamente, os órgãos e entidades responsáveis nas IES em Portugal, incluindo Agências de Avaliação e Acompanhamento. 


\section{Metodologia}

Procurámos com este estudo exploratório obter uma perspetiva "a partir de dentro" sobre a relevância da metodologia do trabalho de grupo no decurso da formação superior em disciplinas afins à Sociologia, identificando as condições em que estas podem ocorrer, bem como os desafios e as dificuldades desse processo. Para o efeito, disseminámos entre estudantes universitários um pequeno inquérito por questionário anónimo, intitulado "Dinâmicas de Grupo e Ensino-Aprendizagem da Sociologia” (IQ-DGSOC/2021). O questionário foi construído na plataforma gratuita Google Forms e disponibilizado online em abril de 2021. O questionário apresentava duas secções principais, num total de 14 questões. Após uma breve caracterização sociodemográfica, auscultaram-se os estudantes sobre o trabalho de grupo em Sociologia. Primeiramente, através de uma escala qualitativa que distinguia entre "Mau", "Indiferente" e "Bom", foi avaliada a utilidade e importância dos trabalhos de grupo para o ensino da Sociologia, para a relação com o(s)/a(s) professor(es)/a(s) e com os/as colegas, na aprendizagem e na avaliação individual. Num segundo momento, convidaram-se os estudantes e as estudantes a descrever textualmente experiências, enunciar vantagens, desvantagens e desafios concomitantes com a avaliação antes efetuada. No conjunto, o questionário continha maioritariamente questões abertas, orientadas para uma lógica exploratória e de descoberta, mais que de verificação (Flick, 2015). Uma amostra acidental e em bola de neve, constituída voluntariamente por estudantes das diversas instituições de ensino superior de pertença das autoras, permitiu recolher um conjunto de informação aprofundada sobre o lugar das dinâmicas de grupo no ensino-aprendizagem da sociologia. Após validação e tratamento inicial, a informação foi submetida a uma análise estatística exploratória. De modo complementar, e no caso particular das questões abertas, foi utilizado o N Vivo12 da (C) QSR International para desenvolver uma análise qualitativa de conteúdo de tipo temático-categorial (Bardin, 1977; Neuendorf, 2017), apoiada num procedimento misto, de tipo fechado e à milha. $\mathrm{O}$ processo de construção de categorias resulta de um exercício dinâmico e interativo que combina a redução e apresentação de dados assente numa comparação constante com a extração de resultados e verificação de conclusões (Miles et al., 2014). Todas as citações incluídas no corpo do artigo são excertos verbatim extraídos das respostas às questões abertas.

Participaram neste estudo exploratório 53 estudantes, com inscrição ativa na Universidade de Évora (22), Universidade de Lisboa (14) e Universidade do Minho (17), num curso de licenciatura (31) ou mestrado (22). Quem respondeu frequenta ou frequentou também algumas unidades curriculares de sociologia coordenadas pelas autoras, embora em cursos diferentes, nomeadamente Sociologia, Economia e Gestão da Ciência, Tecnologia e Inovação e Gestão de Recursos Humanos. As idades variam entre os 19 e os 54 anos de idade, numa 
média de 22,9 anos, com um desvio-padrão de 6,7 e a moda 19. A maior parte dos respondentes (41) identificou-se com o género feminino e 12 com o género masculino. Lembremos que, nos três ciclos de estudo, a população estudante é maioritariamente feminina.

\section{Resultados}

\subsection{Importância do trabalho de grupo no ensino-aprendizagem da Sociologia}

A maior parte dos e das estudantes que respondeu ao questionário classificou a metodologia de trabalho em grupo como "Boa." Esta avaliação é transversal às diversas dimensões consideradas, designadamente, no que respeita à utilidade dos trabalhos de grupo para o ensino dos conteúdos programáticos da sociologia (47), mais-valia na relação com os/as colegas (40), importância na aprendizagem individual (39), enriquecimento da relação com o(s)/a(s) professor(es)/ a(s) (35) e, por fim, importância na avaliação individual (34).

As dimensões que colhem maior peso da avaliação "Indiferente" são as que se relacionam com a mais-valia na relação com o(s)/a(s) professor(es)/a(s) (14), importância na avaliação individual (11) e na aprendizagem individual (10). Quanto às dimensões que colhem maior peso da avaliação "Mau”, estas prendem-se, principalmente, com a importância dos trabalhos de grupo na avaliação individual (8) e no estreitamento da relação com os/as colegas (6).

Não obstante a transversalidade da avaliação de "Bom" nas diversas dimensões consideradas em torno da metodologia do trabalho de grupo, a análise das questões abertas possibilita ilustrar as avaliações efetuadas. Também permite identificar uma certa ambiguidade que, mesmo assim, acompanha o reconhecimento da importância desta metodologia, mesmo em situações em que o próprio trabalho de grupo surge representado como foco de "desigualdade" e de "injustiça".

\subsection{Aprender mais e melhor}

De modo transversal, valoriza-se a metodologia do trabalho de grupo, por oferecer contextos para se aprender "mais", mas também "melhor": i) permite explorar os conteúdos programáticos a partir das experiências do e da estudante, tendo em conta as suas dúvidas e dos comentários; ii) aumenta a frequência e a diversidade de problemas com que o grupo tem de se confrontar, exigindo interação e gestão dos vários inputs (e.g. ideias, pesquisa, recolha, análise) dentro de um determinado prazo. É esta a orientação do excerto seguinte que ilustra o posicionamento da maior parte das respostas que justificam por que razão consideram a metodologia "boa": 
Os trabalhos de grupo permitem um maior aprofundamento dos conteúdos, bem como a aplicação dos conteúdos programáticos para além da componente expositiva dada em aula. Estes também permitem uma maior compreensão através do debate com os elementos dos grupos e através de pesquisas feitas de form a a realizar o trabalho.

No sublinhar do carácter diferente de aprendizagem potenciada pelos trabalhos de grupo, os estudantes e as estudantes assinalam, também, as vantagens que esta metodologia oferece por relação com as provas escritas. Enquanto essas apelam mais a um conhecimento temporário, assente na "memorização", os trabalhos de grupo, porque obrigam à "adaptação" e "criatividade", promovem aprendizagens "sustentadas" e "duradoiras." Como se refere numa resposta:

[Os trabalhos de grupo] São perfeitos meios de interiorizar os conteúdos programáticos de forma prática ao invés de uma simples memorização, com o objetivo de realizar uma prova escrita individual.

A complementar esta ideia, refere-se com frequência que o trabalho de grupo possibilita uma aprendizagem "prática", que aproxima e "treina" para os desafios do "mundo real".

Para a nossa vida profissional o trabalho de grupo é muito importante e essencial, por isso, nestes trabalhos de grupo é como se fosse um "treino" para o futuro.

\subsection{Aprender coisas novas, de forma diferente}

No conjunto de experiências consideradas como marcantes, um misto de "novidade" e "diferença" parece contribuir para reconhecer na metodologia do trabalho de grupo uma aprendizagem significativa ao nível da Sociologia, como se enuncia:

A análise de controvérsias foi uma experiência nova para mim em termos de trabalhos de grupo. É um método diferente daquele que estamos habituados a seguir no ensino superior, no entanto não quer dizer que seja mau, é simplesmente diferente (...) A análise de controvérsias é bastante positiva porque apresenta uma espécie de brainstorming sobre o tema analisado, o que pode trazer mais visões e opiniões que podem ser úteis na resolução dessa controvérsia. 
Segundo o excerto em epígrafe, na perspetiva da população estudante, o trabalho de grupo permite uma aprendizagem "diferente" porque assenta numa aprendizagem em relação direta "com os outros" significativos no processo, "em conjunto" e "de forma próxima." Os "outros" são colegas, professores e também elementos fora da academia com quem interagem na realização do trabalho. Neste domínio, referência a técnicas específicas como o brainstorming ou, mais genericamente, ao "debate" e à "troca de ideias" são frequentes enquanto geradoras de um espaço de aprendizagem que fomenta a autonomia e a aquisição de competências no domínio particular da sociologia, tal como ilustram os excertos seguintes:

É ótimo a utilidade dos trabalhos de grupo para o ensino dos conteúdos programáticos da sociologia. O facto de estarmos a aprender em conjunto, de partilharmos ideias, de aprendemos uns com os outros a melhorar as nossas capacidades e, para além disso, de tirarmos dúvidas uns com os outros é um a forma bastante interessante de aprender sociologia.

[O trabalho de grupo proporciona] um sentido de proximidade que, inconscientemente, proporciona um melhor fluir da comunicação $e$, ainda, uma preparação mais capaz para o futuro dos alunos no mundo do trabalho.

Entre os "outros" significativos, destaca-se o papel dos pares e dos professores, os quais contribuem de forma distinta, embora complementar, para este processo pelo debate de ideias que promovem. No caso dos pares, a maior proximidade e horizontalidade de relação promovem, na perceção dos e das estudantes, um espaço de "partilha", "afinidade" e "crescimento", do qual há que retirar partido, não apenas para o trabalho em si, como também para o crescimento individual de cada estudante. Por isso, entende-se que enfatizem a "colaboração" entre pares:

Aprendemos com as formas de trabalho uns dos outros. Alguns elementos do grupo têm formas de trabalho muito boas e conseguimos aprender bastante se estivermos dispostos a colaborar e a aprender a forma como cada um trabalha; assim, criamos a nossa própria forma de trabalho.

\subsection{Aprender sobre si e sobre os outros, soft skills e o currículo (in) visível}

Os conteúdos das afirmações dos e das estudantes sobre os contributos associados à metodologia do trabalho de grupo estão estruturalmente suportados em dois eixos semânticos: i) a dinâmica da aprendizagem, realizada em 
colaboração constante designadamente com os pares e da "disponibilidade" docente; e ii) a aprendizagem de competências potencialmente valorizáveis no mercado de trabalho.

Destas competências, as mais vezes mencionadas são a comunicação, tanto a nível da escrita, como da oralidade. Outras, mais relacionadas com a "atitude", como a responsabilidade, a cooperação, ou a liderança e a inteligência emocional são também referidas, embora com menos frequência. Um excerto que revela alguma reflexividade sobre este assunto é o seguinte:

Os trabalhos de grupo contribuem para um maior autoconhecimento. São ótimos para adquirir novos conhecimentos e desenvolver soft skills, como o trabalho em equipa, a comunicação, a inteligência emocional, entre outras.

$\mathrm{Na}$ sequência do que dissemos, este conjunto de competências, que podem ser designadas sob a nomeação soft skills, são reconhecidas nas respostas ao questionário como valorizáveis "no mercado de trabalho onde essas competências serão úteis", ainda que exijam um certo tempo a serem trabalhadas, como se observa na intervenção abaixo:

Um trabalho de grupo envolve diferentes pessoas com diferentes competências, competências essas que são passadas de um membro para os outros, reforçando assim a aprendizagem individual de skills que não tínhamos antes de começar o trabalho.

\subsection{Dilemas e tensões: o lado oculto do trabalho de grupo}

No conjunto das respostas obtidas, uma tensão latente, não resolvida entre vantagens e desvantagens associadas aos trabalhos de grupo, parece atravessar as experiências de muitos estudantes. Disto mesmo dão conta algumas expressões utilizadas para descrever diversas questões: "um pau de dois bicos", "dilema" ou "paradoxo."

\subsection{Constituição e composição}

Os discursos enfatizam muitas dificuldades que surgem no funcionamento dos trabalhos de grupo, as quais aparecem associadas aos modos de constituição e composição. Em concreto, o modo diferente de encarar os resultados de aprendizagem por parte dos vários elementos do grupo torna-se, por vezes, foco de tensão: 
Aquando do início da licenciatura, eu e os meus colegas não nos conhecíamos bem, era sempre uma dúvida com quem devia realizar trabalhos de grupo, então fiquei com dois colegas que não gostam muito de trabalhar e outro que até trabalha, mas é do mais minimalista possível.

Observa-se que os trabalhos de grupo oferecem contextos de elevada competição, inclusive interna, seja por atenção pelo corpo docente, seja pela obtenção de notas mais elevadas, o que gera tensões entre estudantes, principalmente, como também ilustra o excerto apresentado acima, quando há ritmos e expectativas de avaliação distintos e diferenciais.

\section{Papéis nos grupos de trabalho: líderes, colaborações fantasma e "salva-vidas"}

Assim, um obstáculo ao bom funcionamento do GT parece ser a dificuldade em concretizar aquilo que está na sua essência: a participação de todos os elementos nos propósitos definidos. De um modo geral, reconhece-se a mais-valia da diversidade de estudantes em presença para a construção do conhecimento, porém, a diversidade pode ser obstaculizante à concretização dos objetivos. Como ilustra o excerto infra, isto pode acontecer devido a estilos de personalidades distintas, mas também a diferentes disponibilidades de tempo e graus de envolvimento nas tarefas.

Já vivenciei muitas situações em trabalhos de grupo na minha licenciatura. Um a das que me marcou bastante foi a de realizar trabalhos com um grupo, em que inicialmente tínhamos tarefas bem repartidas, no entanto, depois de algum tempo, uma colega começou aos poucos a adotar uma posição de líder, em que não partilhava do mesmo nível de trabalho que nós, mas sim uma menor quantidade e passava mais tempo a tentar corrigir a parte dos outros integrantes, e muitas vezes estas correções eram infundadas. Tinha ainda outra colega de grupo que tinha mais dificuldades de aprendizagem e ficava sempre com as partes mais fáceis dos trabalhos, por exemplo, fazer o layout do powerpoint. Noutro grupo de trabalho duas colegas tiveram uma pequena divergência, uma delas desde então passava o tempo todo a falar mal da outra colega, e isto estava a diminuir a produtividade do grupo e a criar um mau ambiente.

Se, por um lado, os trabalhos de grupo podem servir para ajudar a identificar ou aprimorar capacidades de liderança, por outro, são muitas vezes o local de afirmação de ideias, as quais, por sua vez, servem para afirmar pequenos e grandes egos que geram múltiplas tensões, ainda que seja algo que implica o 
desenvolvimento de estratégias comunicacionais, refletidas no entendimento de que se trata de diferenças com as quais é necessário "aprender a lidar."

Para mim, ou seja, segundo o meu caso particular, os trabalhos de grupo vêm aumentar uma das minhas skills, a capacidade de liderança. Anda tudo muito à volta disso... O saber aceitar a opinião do outro colega, porque sei perfeitamente que quando chegar ao mercado de trabalho vou ter de lidar com diferentes pessoas e opiniões. É quase como um treino para isso mesmo, para potencializar algo que eu já tenho, e criar uma certa empatia, e espírito de grupo de trabalho...

(...) as pessoas relacionam-se bem até aparecerem os trabalhos de grupo, até cada um ter a sua opinião e não levar a sua a avante. Muitas vezes, sentem que o outro faz menos do que ele e há algum conflito de egos.

Sob o prisma da interação e das relações de poder que se instalam no grupo, o equilíbrio não é fácil: "Pode haver pontos de vista diferentes, o que é bom para haver uma partilha de ideias, e pode ser mau se todos os indivíduos defenderem a sua com "unhas e dentes", dificultando a negociação, principalmente quando lidam com pouco tempo para a elaboração do trabalho.

No geral, há uma tendência para os contextos de trabalho de grupo afirmarem princípios de orientação coletivista, como propostos por Hofstede (2011). Tacitamente, aceita-se a presença nos trabalhos de grupo com estudantes a que chamam "fantasma", ou seja, que, pelas mais diversas razões, não contribuem como esperado, ainda que, no final, assinem o trabalho e dele retirem uma avaliação igual aos demais elementos.

Nos trabalhos de grupo conseguimos desenvolver aptidões em termos de soft skills, mas não são todos os alunos que adquirem conhecimentos, pois há sempre um conjunto de alunos que não faz o trabalho, só assinam o nome.

A informação que recolhemos permite estabelecer que os trabalhos de grupo parecem também fazer emergir a figura do "salva-vidas", alguém que, seja devido às suas características pessoais (e.g. "perfeccionista", "cumpridor”, "motivado", etc.), seja devido ao sentido de responsabilidade e compromisso para com a vida e para com os objetivos académicos, toma nas suas mãos as rédeas da elaboração do trabalho, mesmo que isso crie em si sentimentos ambíguos, ora de cumprimento ora de injustiça. 


\section{Avaliação, justiça e a ética do compromisso}

A questão da avaliação dos trabalhos de grupo traz ao de cima considerações sobre a justiça na apreciação avaliativa por parte do corpo docente, em torno do contributo individual e de grupo. De um modo geral, os estudantes e as estudantes reconhecem que uma "boa nota" depende do envolvimento de todos/as e que, consequentemente, quando isso não se verifica, todos ficam prejudicados.

A cooperação entre colegas num trabalho de grupo pode levar a que aumentem em conjunto a sua nota individual, isto se o grupo trabalhar todo para o mesmo. Quando um trabalha mais do que outro, pode estar a ser prejudicado pelo colega.

Já o facto de um ou uma estudante tomar em si as rédeas do processo e concluir a elaboração do trabalho sem o envolvimento de todos, mesmo que isso permita a conclusão da disciplina e a obtenção de uma nota positiva, é considerado duplamente "injusto." Por um lado, porque esta situação impede que o grupo potencie o trabalho de equipa para alcançar uma nota mais elevada; por outro, porque mesmo assim, o trabalho de quem "trabalhou mais" acaba por não ser reconhecido pelo professor e fica diluído numa nota "igual para todos."

Adoro trabalhos de grupo, sinto que aprendo muito mais, no entanto, tenho sempre de fazer mais do que os outros, o que me stressa e faz perder mais tempo do que era suposto e a nota é igual para todos.

As estratégias que os e as estudantes propõem para lidar com esta situação são de duas ordens diferentes. A primeira incide sobre o corpo docente e pugna por "maior justiça" no processo de avaliação. Em concreto, estratégias que conciliem uma componente de avaliação individual, intragrupal, a par de outra componente de grupo são frequentemente citadas como "mais justas" para aferir o "real contributo" de cada um dos membros do grupo no todo. No que toca ao corpo discente, insiste-se numa ética do compromisso que implique diretamente os estudantes nos processos de trabalho, mas também na avaliação. Por exemplo, sugere-se a adoção de reportes em que os vários elementos do grupo são chamados a descrever o real contributo de cada um para o trabalho apresentado, ou uma avaliação de cada membro do grupo sobre a prestação dos demais.

Seria interessante que fosse feita uma autoavaliação de grupo em que cada membro fazia a sua autoavaliação juntamente com a dos seus 
colegas. Deste modo, através da sinceridade dos alunos, seria possível ao professor perceber os níveis de participação dentro do grupo. No entanto, esta autoavaliação grupal poderia contribuir para a diferença entre as avaliações finais de membros do mesmo grupo, o que levaria ao descontentamento de uns, à falsidade de resposta de outros na autoavaliação, e à tentativa de controlo e liderança do trabalho por parte de alunos que se quisessem destacar e obter avaliações finais superiores às dos colegas.

O carácter "reservado" ou "anónimo" da informação, seja porque segue num relatório individual, seja porque é feita através de uma aplicação informática, parece ser a estratégia preconizada pelos estudantes para obviar a dificuldade que persiste em admitir de forma ex plícita a desigual contribuição de cada um para o trabalho de grupo.

\section{Discussão}

Os resultados obtidos são exploratórios e limitados pelas características do estudo empírico que realizámos. Ainda assim, tratando-se de informação de carácter qualitativo, que incide sobre narrativas dos estudantes e das estudantes, permite estabelecer algumas ideias fundamentais relativamente ao modo como as metodologias de trabalho em grupo, para além da aquisição de conceitos e conhecimentos teóricos em geral, desempenham um papel de relevo no treino de várias aprendizagens em Sociologia. A negociação, a mediação e a distribuição de tarefas são as três questões principais. Se considerarmos que algumas das competências básicas da atividade do sociólogo envolvem a comunicação e a organização de fluxos de trabalho e de informação, então o trabalho de grupo proporciona, nos vários anos de formação, contextos significativos de aprendizagem para os estudantes. Todavia, a informação recolhida revela várias fontes de ambivalência na forma como os estudantes entendem este método de ensino-aprendizagem.

Os trabalhos de grupo acarretam processos de interação complexos. Nas descrições que analisámos observa-se que nem sempre são acolhidos de forma muito entusiasta pelos próprios estudantes, que frequentemente lhes associam diversas dificuldades relacionadas com a gestão do poder desigual no grupo, o investimento em termos de tempo a que obrigam ou a assimetria na colaboração por parte dos vários constituintes. O trabalho em grupo consiste num processo social onde podem ocorrer riscos de desigualdade nos contributos dos vários elementos. Inclusive, pode até acolher percursos mais "clandestinos", nos quais alguns estudantes ficam com o nome nos trabalhos finais sem que tenham investido no desenvolvimento do projeto. A observação permite estabelecer que este aspeto pode gerar duas lógicas de "sobrevivência", ambas 
menos alinhadas com os objetivos ideais que presidem à dinâmica de grupo e que constatamos através da análise das respostas.

A primeira lógica de sobrevivência identificada - foco no próprio trabalho escrito e oral e menosprezo pela apresentação dos trabalhos dos outros - revela um entendimento muito utilitário do GT; a segunda lógica de sobrevivência - a da comparação com os outros grupos - resulta em atitudes de vigilância, quer dos trabalhos dos colegas, quer do acompanhamento do corpo docente e, de igual modo, resulta também em situações de menosprezo pela dinâmica coletiva e consequente afirmação do individualismo com o qual o TG é muitas vezes perspetivado. Nas respostas perpassam diferentes modalidades de GT. Em algumas UC, os GT são definidos pelo corpo docente que agrega os estudantes em grupos, desde o início do semestre, a partir da lista de inscritos. Esta modalidade parece pretender "simular" ou "confrontar" os estudantes com situações de trabalho que se antecipam "idênticas". Quando a constituição dos GT é imposta pela equipa docente, e quando isso acontece nos últimos anos de formação, as dificuldades de relacionamento podem ser mais acentuadas devido às disponibilidades relacionadas com a (in)disponibilidade de tempo, heterogeneidade de contextos de vida, quotidianos pessoais e académicos, os quais muitas vezes não são, ou não vêm a ser, do conhecimento do corpo docente (e.g., UC em atraso, atribuições familiares diversas, horários de trabalho, deslocações, etc.).

As várias situações acima descritas vêm também mostrar a necessidade de se reconhecer, como aliás faz o paradigma da aprendizagem colaborativa, que os alunos não chegam "equipados" para o trabalho em grupo (Millis, 2014). A este propósito, Millis (2014) refere que alguns docentes organizam sessões de liderança e facilitação para que os elementos do grupo se possam apoderar das técnicas mais básicas do trabalho em grupo, nomeadamente a escuta ativa. Os resultados indicam ser essencial que todos os membros do grupo dediquem tempo de observação sobre o que se passa no grupo (como, por exemplo, identificar se existe um elemento menos empenhado), levando à discussão e resolução pelo grupo destes problemas. Também num grupo deve haver a atenção suficiente em estimular a participação dos mais introvertidos e, se necessário, dosear a intervenção dos mais extrovertidos. Isto pode ser incentivado ao nível da docência e, também, estimulado dentro do grupo. Finalmente, a capacidade de organizar de forma equilibrada a discussão e promover o avanço positivo do trabalho é uma competência essencial no trabalho de grupo. Acontece, no entanto, que o paradigma de ensino orientado para a reflexividade, para a transformação de hábitos e olhares do mundo direcionados para a ação é, declaradamente, exigente em termos de recursos humanos e materiais, espaço e tempo, bem como de política educativa (Clegg, 2005). A experiência das autoras nas três instituições onde o questionário foi aplicado, bem como as várias justificações aventadas pelos estudantes inquiridos que remetem para as 
dificuldades e constrangimentos dos docentes, permitem estabelecer que estes recursos materiais e humanos são escassos e/ou pouco desenvolvidos, entre os quais salas de aulas equipadas com material didático adequado à dinâmica de grupo e de projeto para os cursos de Sociologia e Ciências Sociais, e a possibilidade de aumento do tempo letivo dos docentes dirigido ao trabalho de grupo com alunos, nas mais diversas temáticas.

\section{Conclusão}

As questões relacionadas com a colaboração e o funcionamento de grupos são temas clássicos de estudo na Sociologia. As metodologias de trabalho em grupo são favorecidas por contextos culturais que valorizam a confiança e a perceção sobre o desempenho individual face às recompensas esperadas. De uma forma global, e atendendo aos estudos e reflexões existentes, é possível confirmar que o trabalho de grupo não pode ser entendido ad hoc para incentivar os estudantes a realizar trabalho autónomo porque, em função das suas finalidades e do acompanhamento realizado, pode não oferecer contex to de reflexividade adequado, nem sobre os conteúdos, nem sobre o processo. A informação recolhida sustenta a relevância da articulação profunda entre os objetivos pretendidos e a metodologia de trabalho de grupo, o que não pode ser feito à margem de um esclarecimento cabal junto dos e das estudantes. Com efeito, estes ainda trazem representações sobre o ensino transmissivo e resistem bastante às formas mais ativas e autónomas de trabalho. Como propõem Michaelsen e Sweet (2008), é importante que o trabalho de grupo seja conjugado com instrumentos de avaliação regular, realizado na base de indicadores tais como o planeamento das diferentes fases de avaliação, a definição clara de objetivos e a integração por parte dos docentes através de tutorias.

Tal como Machado (2020) demonstra, a Sociologia em Portugal acumula hoje uma trajetória consolidada, sensível aos novos perfis profissionais procurados no mercado de trabalho, cujas tendências atuais enfatizam as competências consideradas "suaves", entre as quais a colaboração, a comunicação e o trabalho em equipa. Assim, qualquer proposta de reflexão e de alteração pedagógica implica um vasto leque de variáveis que são tanto de caráter institucional, como relacionáveis com as circunstâncias políticas e sociológicas que caracterizam os modos de vida nas sociedades contemporâneas. Por esta razão, o conjunto de conclusões a que chegámos devem ser consideradas no contexto mais amplo que explica a situação da Sociologia frente a outras áreas. Ao mesmo tempo, a constatação da sua limitação e o carácter provisório não deve senão incentivar-nos ao aprofundamento de uma investigação que possa contemplar outras variáveis, incluindo sociodemográficas e socioprofissionais, nas representações, expectativas e práticas do trabalho em grupo. 


\section{Referências bibliográficas}

A3ES. AGÊNCIA DE AVALIAÇÃO E ACREDITAÇÃO DE CURSOS DO ENSINO SUPERIOR. (2021). Acreditação de Ciclos de Estudos [em linha]. Lisboa: A3ES [consult. 01 abr. 2021]. Disponível em https://www.a3es.pt/pt/acreditacao-e-auditoria/ resultados-dos-processos-de-acreditacao/acreditacao-de-ciclos-de-estudos.

ATHERTON, James S. - Learning and teaching: Deep and surface learning [em linha]. 2009. [consult. 01 abr. 2021]. Disponível em https://www.learningandteaching.info/\% 20learning/ deepsurf.htm.

BARDIN, Laurence - A nálise de conteúdo. Lisboa: Edições 70, 1977. ISBN: 9789724415062.

BERGER, Peter - A sociologia como forma de consciência. Petrópolis, RJ: Ed. Vozes, 1986. ISBN : 85-7430-053-5.

BULAN DA Jennifer Roebuck; FRYE, Shelby - Transforming Introductory Sociology with TeamBased Learning: Sufficient Value and Surmountable Challenge? Teaching Sociology [em linha]. 48: 4 (2020), p. 272-282. [consult. 01 abr. 2021]. Disponível em: https://journals. sagepub.com/doi/pdf/10.1177/0092055X20947175. ISSN : 0092055x.

CALLON, Michel - Pour une sociologie des controverses technologiques. Fundamenta Scientiae. UK. ISSN 0160-7847. 2 : 3/4 (1981), p. 381-399.

CAUlfiEld, Susan L.; HODGES, Caroline P. - Teaching Social Science Reasoning and Quantitative Literacy: The Role of Collaborative Groups. Teaching Sociology [em linha]. 34: 1 (2006), p. 39-53. [consult. 01 abr. 2021]. Disponível em: https://journals.sagepub.com/doi/ pdf/10.1177/0092055X0603400104. ISSN : 0092055X.

CARIA, Telmo; CÉSAR, Filipa; BRITES, Raquel - A profissionalização da Sociologia e o uso dualístico das Ciências Sociais. Configurações [em linha]. 9 (2012), p. 15-36. [consult. 01 abr. 2021]. Disponível em: https://journals.openedition.org/configuracoes/1083\#quotation. ISSN : 2182-7419.

CLEGG, Sue - Theorising the mundane: The significance of agency. International Studies in Sociology of Education [em linha]. 15: 2 (2005), p. 149-164. [consult. 01 abr. 2021]. Disponível em: https://www.tandfonline.com/doi/pdf/10.1080/09620210500200137?needA ccess=true. ISSN : $1747-5066$.

COSTA, António F. - Sociólogos: associativismo inclusivo versus fechamento corporativo. Sociologia Online [em linha]. 18 (2018), p. 81-87 [consult. 01 abr. 2021]. Disponível em: https://revista.aps.pt/wp-content/uploads/2019/03/Sociologia APS182018.pdf\#page=81. ISSN : 1647-3337.

DAILEY, Beth - Creating significant deep learning experiences (The Cross Papers, No. 14). Phoenix, AZ: League for Innovation in the Community College, 2011. ISBN : 9781931300636.

DEWEY, John - Experiência e educação, Petrópolis, RJ: Ed. Vozes, 2011 ISBN : 9788532639363.

DIAS, Diana - Resultados de Aprendizagem: da intenção do professor à ação do estudante. In ALMEIDA, Leandro (org.) - Estudantes do Ensino Superior: Desafios e Oportunidades. Braga, Portugal: ADIPSIEDU, 2019. ISBN: 978-989-99517-2-3. p. 115-136.

DIAS, Diana (coord) - O que se diz que se aprende: resultados de aprendizagem do ensino superior em Portugal. Lisboa: A3ES Readings, s.d.. [consult. 01 abr. 2021]. Disponível em: https://www.a3es.pt/sites/default/files/LO_Livro.pdf.

DIAS, Diana; SOARES, Diana - Learning outcomes in Higher Education: Designing a conceptual map for Portuguese academia. In INTED2017 Proceedings. Valencia: IATED, 2017. ISBN: 978-84-617-8491-2. p. 9188-9194.

DOCH Y, Filip; SEGERS, M.S.R. P.; VAN DEN BOSSCHE, P.G.; GIJBELS, D. - Effects of problem-based learning: a meta-analysis. Learning and Instruction [em linha]. 13: 5 (2003), 
p. 533-568 [consult. 01 abr. 2021]. Disponivel em: https://www.sciencedirect.com/science/ article/pii/S0959475202000257. ISSN : 1873-3263.

EDLAB - The UM Handbook for PBL \& Research Skill [em linha]. Maastricht: Maastricht University Institute for Education Innovation, 2017. [consult. 01 abr. 2021]. Disponivel em: https://edlab.nl/wp-content/uploads/2017/10/PBL-Research-Skills-Handbook-1.pdf.

EGLITIS, Daina S.; BUNTMAN, Fran L.; ALEXANDER, Dameon V. - Social Issues and Problem-based Learning in Sociology: Opportunities and Challenges in the Undergraduate Classroom. Teaching Sociology [em linha]. 44: 3 (2016), p. 212-220. [consult. 01 abr. 2021]. Disponível em: https://journals.sagepub.com/doi/pdf/10.1177/0092055X16643572. ISSN: $0092055 \mathrm{X}$.

FLICK, Uwe - Métodos Q ualitativos na Investigação Científica. Lisboa: Monitor, 2015. ISBN: 9789729413674.

FREIRE, Paulo - A pedagogia do oprimido. Porto: Edições Afrontamento, 2018. ISBN :729723616651.

HOFSTEDE, G. - Dimensionalizing Cultures: The Hofstede Model in Context. Online Readings in Psychology and Culture [em linha]. 2: 1 (2011), p. 1-26. [consult. 01 abr. 2021]. Disponível em: https://doi.org/10.9707/2307-0919.1014.

HUGGINS, Christopher M.; STAMATEL, Janet P. - An Exploratory Study Comparing the Effectiveness of Lecturing versus Team-based Learning. Teaching Sociology [em linha]. 43: 3 (2015), p. 227-235. [consult. 01 abr. 2021]. Disponível em: https://journals.sagepub.com/doi/ pdf/10.1177/0092055X15581929. ISSN : 0092055X.

LAHIRE, Bernard - Viver e interpretar o mundo social: para que serve o ensino de sociologia?. Revista de Ciências Sociais. Fortaleza. ISSN 2318-4620. 45: 1 (2014), p. 45-61.

LEW IN, Kurt - Resolving social conflicts and Field Theory in Social Science: Selected theoretical papers. New York: Harper \& Brothers, 1951. ISBN: 1557984158

MACHADO, Fernando L. - Sociologia em Portugal. Da Pré-história à Institucionalização Avançada. Porto: Edições Afrontamento, 2020. ISBN : 9789723617924.

MICH AELSEN, Larry K.; SWEET, Michael - Team-based learning. New Directions for Teaching \& Learning [em linha]. 128 (2011), p. 41-51. [consult. 01 abr. 2021]. Disponível em: https://onlinelibrary.wiley.com/doi/epdf/10.1002/t1.467. ISSN :1536-0768.

MICHAELSEN, Larry K.; SWEET, Michael - The Essential Elements of Team-Based Learning. New Directions for Teaching \& Learning [em linha]. 116 (2008), p. 7-27. [consult. 01 abr. 2021]. Disponível em: https://onlinelibrary.wiley.com/doi/epdf/10.1002/t1.330. ISSN : $1536-0768$.

MILES, Matthew B.; HUBERMAN, A. Michael; SALDAÑ A, Johnny - Q ualitative data analysis: A methods sourcebook. Los Angeles: Sage, 2014. ISBN: 978-1506353074.

MILLIS, Barbara J. - Using cooperative structures to promote deep learning. Journal on Excellence in College Teaching. Miami. ISSN-1052-4800. 25: 3-4 (2014), p. 139-148.

MILLS, Charles Wright - A imaginação sociológica. Rio de Janeiro: Zahar Editores, 1982. ISBN : 19752461421.

MONSON, Renee - Groups That Work: Student Achievement in Group Research Projects and Effects on Individual Learning. Teaching Sociology [em linha]. 45: 3 (2017), p. 240-251. [consult. 01 abr. 2021]. Disponível em: https://journals.sagepub.com/doi/ pdf/10.1177/0092055X17697772. ISSN : 0092055X.

MORRIS, Patricia; IDA, Aya Kimura; MIGLIACCIO, Todd; TSUKADA, Yusuke; BAKER, Dylan -Collaborative Learning in Sociology Research Methods Courses: Does Race Matter? Teaching Sociology [em linha]. 48: 4 (2020), p. 300-312. [consult. 01 abr. 2021]. Disponível em: https://journals.sagepub.com/doi/pdf/10.1177/0092055X20953876.

NEUENDORF, Kimberly A. - The Content Analysis Guidebook. London: Sage, 2017. ISBN: 9781412979474. 
PAPE, Max A.; MILlER, D. Paul - New Approaches to the Teaching of Sociology: Team Learning and Small Group Dynamics. The American Sociologist [em linha]. 2: 2 (1967), p. 93-95. [consult. 01 abr. 2021]. Disponível em: http://www.jstor.org/stable/27701247. ISSN: 19364784.

QS - Learning in lockdown: how students are experiencing education now. London: QS Quacquarelli Symonds, 2021. [consult. 01 abr. 2021]. Disponível em: https://www.qs.com/ portfolio-items/learning-in-lockdown-how-students-are-experiencing-education-now/.

RAMOS, Madalena; CAPUCHA, Luís; TAVARES, Inês (Org.) - Quem são e o que fazem os sociólogos em Portugal?. Lisboa: Mundos Sociais, 2018. ISBN : 978-989-8536-67-9.

SCHEVISBISKI, Renata - Metodologias de ensino de Sociologia: o projeto "O ficina de Ideias" [em linha]. Londrina: UEL (2008), p. 1-11. [consult. 01 abr. 2021]. Disponível em: http:// www.uel.br/grupo-estudo/gaes/pages/arquivos/GT3\% 20Artigo\% 20Renata\% 200 ficina\% 20 de\% 20Ideias.pdf.

SILVA, A. S. - Sociologia e política pública: sobre avanços recentes em Portugal. Análise Social [em linha]. 225: LII 4 (2017), p. 782-803. [consult. 01 abr. 2021]. Disponível em: http://analisesocial.ics.ul.pt/documentos/n225a03.pdf. ISSN : 2182-2999.

SM ITH, Karen S.; CLEGG, Sue; LAW RENCE, Elizabeth; TODD, Malcolm J. - The challenges of reflection: students learning from work placements. Innovations in Education and Teaching International [em linha]. 44: 2 (2007), p. 131-141. [consult. 01 abr. 2021]. Disponível em: https://www.tandfonline.com/doi/full/10.1080/14703290701241042. ISSN: 1470-3300.

STEIN, Rachel E.; COLYER, Corey J.; MANNING, Jason - Student Accountability in Teambased Learning Classes. Teaching Sociology [em linha]. 44: 1 (2015), p. 28-38. [consult. 01 abr. 2021]. Disponível em: https://journals.sagepub.com/doi/pdf/10.1177/0092055X15603429. ISSN : $0092055 \mathrm{X}$.

VEN TURIN I, Tommaso - Diving in magma: how to explore controversies with actor-network theory. Public Understanding of Science [em linha]. 19: 3 (2010), p. 258-273. [consult. 01 abr. 2021]. Disponível em: https://doi.org/10.1177/0963662509102694. ISSN: 1361-6609.

YAVUZ, Devrim Adam - Fronts Matter: The Effectiveness of an "Edited Book" Project in Classical Theory. Teaching Sociology [em linha]. 48: 4 (2020), p. 327-340. [consult. 01 abr. 2021]. Disponível em: https://journals.sagepub.com/doi/pdf/10.1177/0092055X20944454. ISSN : $0092055 \mathrm{X}$.

- Receção: 16.06.2021

- Aprovação: 27.09.2021 